\title{
Production of Higher-quality Plastein from a Crude Single-cell Protein
}

\author{
Masao Fujimaki, Kiyoshi Utaka, Michiko Yamashita \\ and Soichi ARAI \\ Department of Agricultural Chemistry, The University of Tokyo, Tokyo \\ Received May 15, 1973
}

\begin{abstract}
From defatted $n$-paraffin-assimilating yeast cells, a crude protein was obtained by alkaliextraction followed by acid-precipitation. Then the protein was treated with ether until extractable substances were removed exhaustively at this stage. However, at the next stage where the ether-treated protein had been partially hydrolyzed with pepsin, when the hydrolysate was retreated with ether, it was found that ether-extractable substances totalling $270 \mathrm{mg} / 100 \mathrm{~g}$ were obtainable additionally. Chromatographic investigations demonstrated that the substances included significant amounts of aliphatic and aromatic hydrocarbons, some indoles, and a ubiquinone $(n=8)$.

From the protein hydrolysate (substrate) after the above ether-treatment, a plastein was synthesized with Bioprase under the specific conditions. The plastein was obtained as a precipitate when the whole reaction mixture was treated with aqueous ethanol or acetone. The quantity and quality (nitrogen content) of the plastein depended on the ethanol or acetone concentration. Roughly speaking, the higher the concentration, the more the plastein quantity. The converse relation held for the quality; a plastein precipitated by treatment solely with water showed a higher quality than any other case.
\end{abstract}

Attention has been paid on the material in terms of the so-called "petroprotein" since a decade of years ago, because this newly developed protein is probably promising in receiving food application in the near future. However, in a sense of the acceptability that may be one of the most noticeable factors in using a protein material as food, the value of the petroprotein is not always assessable as being satisfactory at present, partly because this protein as well as other time-honored proteins known, usually involves an unfavorable problem that this often carries impurities limiting its unhesitative acceptance-impurities such as flavor components, various types of lipids that may cause secondarily, objectionable flavors, and coloring and fluorescent compounds. In a viewpoint of food science it is of major importance to obtain impurity-free products from crude petroprotein preparations; probably it may be so also from the standpoint of food sanitation in relation to such a hazard as the possible contamination by some carcinogenic hydrocarbons.

We attempted the removal of the impurities by the method of applying exclusively proteinases and some warranted solvents, and succeeded in obtaining an acceptability-improved, protein-like foodstuff (plastein) from a crude petroprotein via its peptic hydrolysate, through the repeated enzyme- and solvent-treatments as shown schematically in Fig. 1.

\section{MATERIALS AND METHODS}

Yeast cells. A dried cell preparation of n-paraffinassimilating yeast (Candida) presented by a commercial maker was used.

Crude protein preparation. From the yeast cell preparation a crude protein fraction was prepared by following the scheme given in Fig. 2.

Protein hydrolysis. The ether-treated protein was dissolved (or suspended) in dil. $\mathrm{HCl}$; the final volume being 5 liters with $\mathrm{pH}$ 1.6. To the solution was added $500 \mathrm{mg}$ of pepsin (a recrystallized preparation from Sigma Chemical Co.), and the mixture incubated at $37^{\circ} \mathrm{C}$ for $2 \mathrm{hr}$ with vigorous shaking. At this stage 

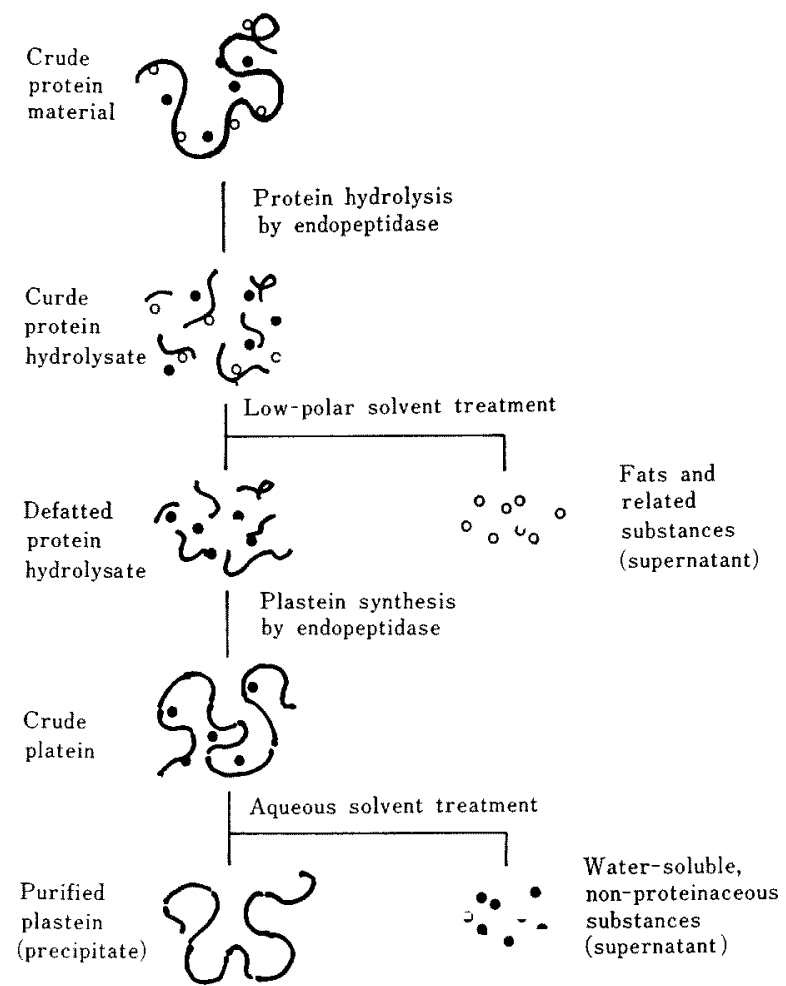

Flg. 1. A Schematic Diagram Showing Procedures of Preparing a Purified Plastein from a Crude Protein Material.

another aliquot $(500 \mathrm{mg})$ of pepsin was added and the system readjusted to $\mathrm{pH} 1.6$. The incubation was continued further for $24 \mathrm{hr}$ in a similar manner.

Indication of the degree of hydrolysis. The method employing trichloroacetic acid was used according to a previous report. ${ }^{11}$

Analysis of ether-extractable substances. Chemical and instrumental methods were used, each case being described in detail in illustrations together.

Plastein synthesis. The neutralized, water-soluble protein-hydrolysate $(10 \mathrm{~g}$ on a dry-matter basis) was dissolved in water; the final volume of the solution being $20 \mathrm{ml}$ with $\mathrm{pH} 6.0$. To this system was added $200 \mathrm{mg}$ of Bioprase (Nagase Sangyo Co.), and the mixture incubated at $37^{\circ} \mathrm{C}$ for $48 \mathrm{hr}$.

Determination of the plastein yield. A precipitate obtained by treatment with aqueous ethanol (acetone) was dried and weighed.

Plastein quality evaluation. The precipitated and supernatant fractions (cf. Fig. 2) were analyzed for nitrogen and sugar contents, ${ }^{2)}$ and for color and fluorescence intensities, to indicate the plastein quality.

\section{RESULTS}

Protein-hydrolytic process

A dried yeast cell preparation was treated with ether for $48 \mathrm{hr}$ using a Soxhlet extraction column $(8 \times 25 \mathrm{~cm})$ to remove most of the ether-extractable substances. From the ethertreated cells a crude protein preparation was obtained through the procedures shown in Fig. 2, with an yield of $85 \%$ on a dry-matter basis. This preparation was retreated with ether similarly to remove residual ether-extractable substances until the content of the so-called "crude fat" became nil apparently. The ether-extractable substances obtained from the above two treatments were combined into one fraction and designated as Etherextractable fraction $\mathrm{I}$; its amount totalling $4.5 \%$ on a dry-matter basis.

The ether-treated preparation of protein was hydrolyzed with pepsin under the described conditions so that the resulting hydro- 


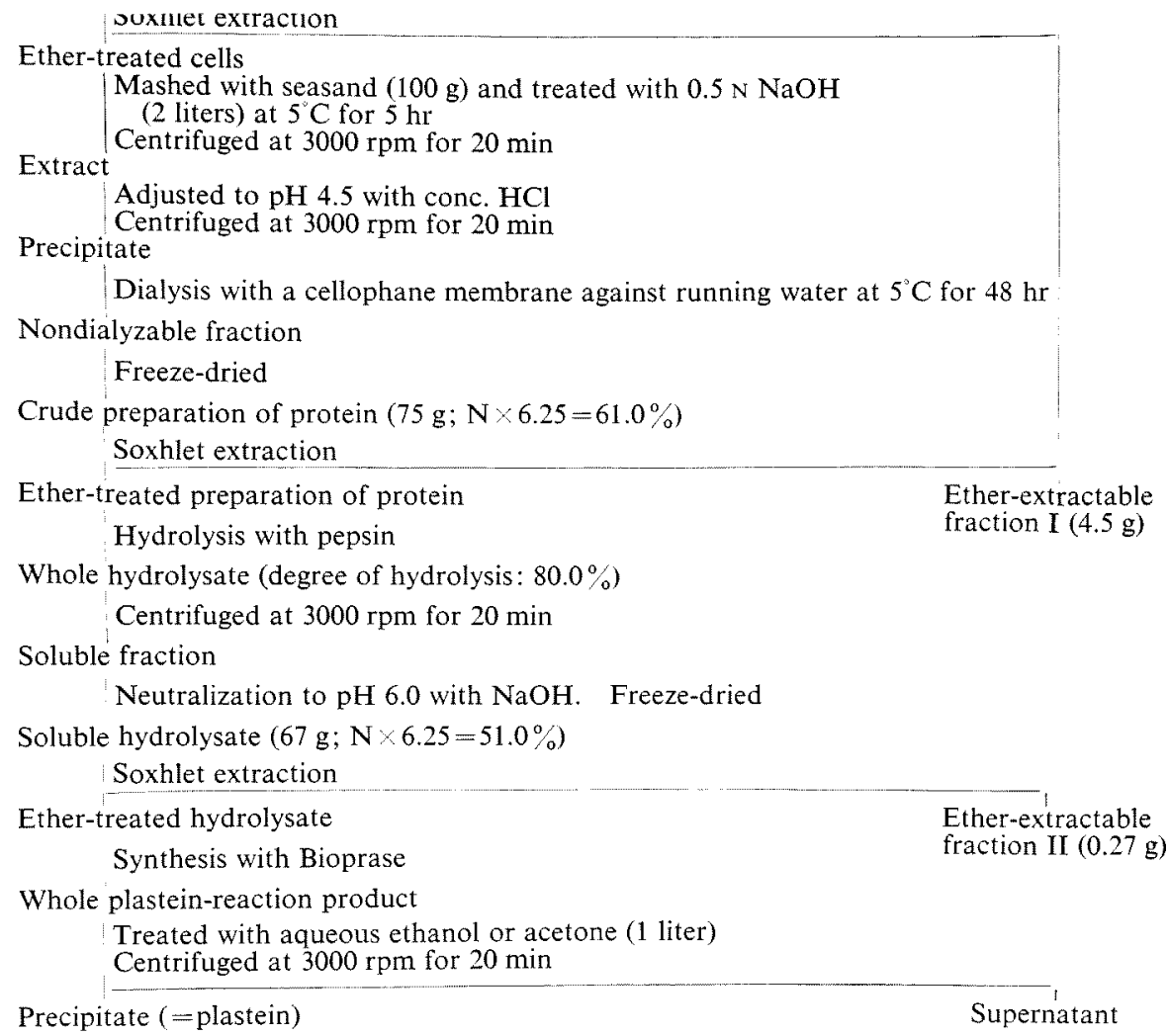

FIG. 2. Procedure for Preparing a Higher-quality Plastein.

Ether-extractable fraction ${ }^{a}$

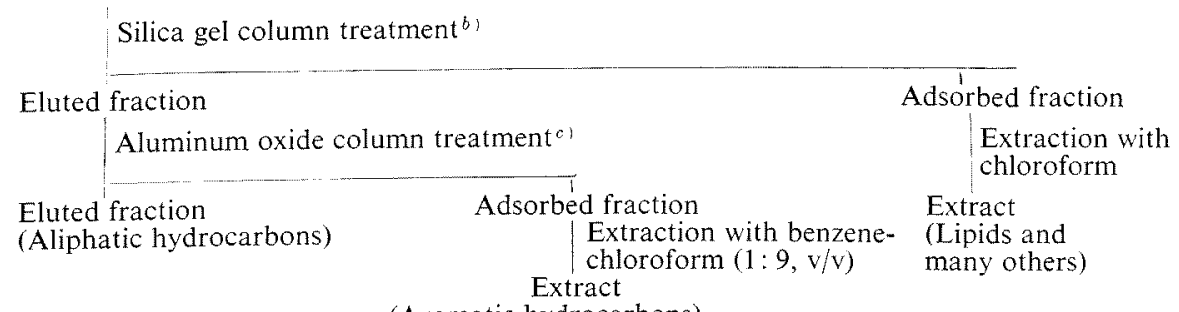

(Aromatic hydrocarbons)

FIG. 3. Procedures for Analysing the Ether-extractable Fractions.

a) One gram, on a dry-matter basis, was submitted to a one-run analysis.

b) A 100-mesh silica gel preparation for chromatographic use (Kanto Kagaku Co.) was packed in a column with $n$-hexane so that the resulting bed size was $4 \times 25 \mathrm{~cm}$. The development was made with $n$-hexane $(300 \mathrm{ml})$ at the flow rate of $1.5 \mathrm{ml} / \mathrm{min}$.

-) An aluminum oxide preparation for chromatographic use (Merck) was activated at $100 \mathrm{C}$ for $2 \mathrm{hr}$. The activated adsorbent was packed in a column with $n$-hexane so that the resulting bed size was $0.8 \times 35 \mathrm{~cm}$. The development was made with a sufficient volume of $n$-hexane at the flow rate of $0.8 \mathrm{ml} / \mathrm{min}$. 


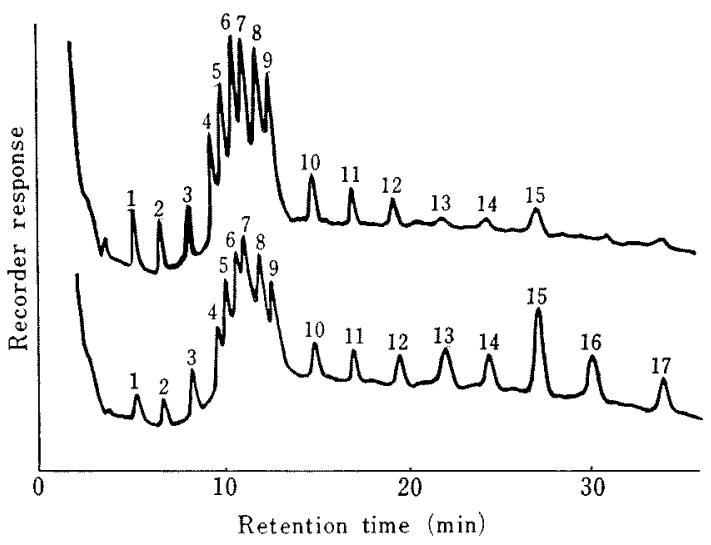

FIG. 4. Gas Chromatograms of Aliphatic Hydrocarbons from Ether-extractable Fractions I (upper) and II (lower).

Apparatus, Shimadzu GC-4A; column, $10 \%$ silicon DC-550/Diasolid M $(0.3 \times 200 \mathrm{~cm}) ;$ temperature, $200^{\circ} \mathrm{C}$; and carrier $\left(\mathrm{N}_{2}\right)$ flow-rate, $35 \mathrm{ml} / \mathrm{min}$.

lysate showed a value of $80.0 \%$ in the degree of hydrolysis. When the hydrolysate, after neutralization and freeze-drying, was again treated with ether by use of a Soxhlet apparatus, ether-extractable substances designated as Ether-extractable fraction II were newly obtained with an yield of $0.27 \%$ on a drymatter basis.
TAble I. IDENTITy of THE Aliphatic HYDROCARBONS

\begin{tabular}{|c|c|c|}
\hline $\begin{array}{c}\text { Peak } \\
\text { No. }\end{array}$ & Identity & Method of identification \\
\hline 1 & n-Undecane & $t_{\mathrm{R}}$ \\
\hline 2 & $n$-Dodecane & $t_{R}$ \\
\hline 3 & $n$-Tridecane & $t_{\mathrm{R}}$ \\
\hline 4 & Tetradecadiene & GC-MSa) $\left(\mathrm{M}^{+}: 194\right)$ \\
\hline 5 & $n$-Tetradecane & $t_{\mathrm{R}}$ \\
\hline 6 & Pentadecadiene & $\mathrm{GC}-\mathrm{MS}^{b /}\left(\mathrm{M}^{+}: 208\right)$ \\
\hline 7 & n-Pentadecane & $t_{\mathrm{R}}$ \\
\hline 8 & Hexadecadiene & GC-MS $\left(\mathrm{M}^{+}: 222\right)$ \\
\hline 9 & $n$-Hexadecane & $t_{\mathrm{R}}, \mathrm{GC}-\mathrm{MS}^{d /}\left(\mathrm{M}^{+}: 226\right)$ \\
\hline 10 & $n$-Heptadecane & $t_{\mathrm{R}}, \mathrm{GC}-\mathrm{MS}\left(\mathrm{M}^{+}: 240\right)$ \\
\hline 11 & n-Octadecane & $t_{\mathrm{R}}, \mathrm{GC}-\mathrm{MS}\left(\mathrm{M}^{+}: 254\right)$ \\
\hline 12 & n-Nonadecane & $t_{\mathrm{R}}, \mathrm{GC}-\mathrm{MS}\left(\mathrm{M}^{+}: 268\right)$ \\
\hline 13 & $n$-Eicosane & $t_{\mathrm{R}}, \mathrm{GC}-\mathrm{MS}\left(\mathrm{M}^{+}: 272\right)$ \\
\hline 14 & n-Heneicosane & $t_{R}, \mathrm{GC}-\mathrm{MS}\left(\mathrm{M}^{+}: 296\right)$ \\
\hline 15 & $n$-Docosane & $t_{R}, \mathrm{GC}-\mathrm{MS}\left(\mathrm{M}^{+}: 310\right)$ \\
\hline 16 & $n$-Tricosane & $t_{\mathrm{R}}, \mathrm{GC}-\mathrm{MS}\left(\mathrm{M}^{+}: 314\right)$ \\
\hline 17 & $n$-Tetracosane & $t_{\mathrm{R}}, \mathrm{GC}-\mathrm{MS}\left(\mathrm{M}^{+}: 338\right)$ \\
\hline $\begin{array}{ll}a) & c \\
b 1 & c \\
c) & C \\
d & 0\end{array}$ & $\begin{array}{l}\text { Fig. } 5 \text { (upper). } \\
\text { Fig. } 5 \text { (upper). } \\
\text { art shown in Fig. } \\
\text { art shown in Fig. }\end{array}$ & $\begin{array}{l}\text { (upper). } \\
\text { (lower). }\end{array}$ \\
\hline
\end{tabular}

Analysis of the ether-extractable fractions

According to the procedures of fractionation shown in Fig. 3, the main ingredients in each

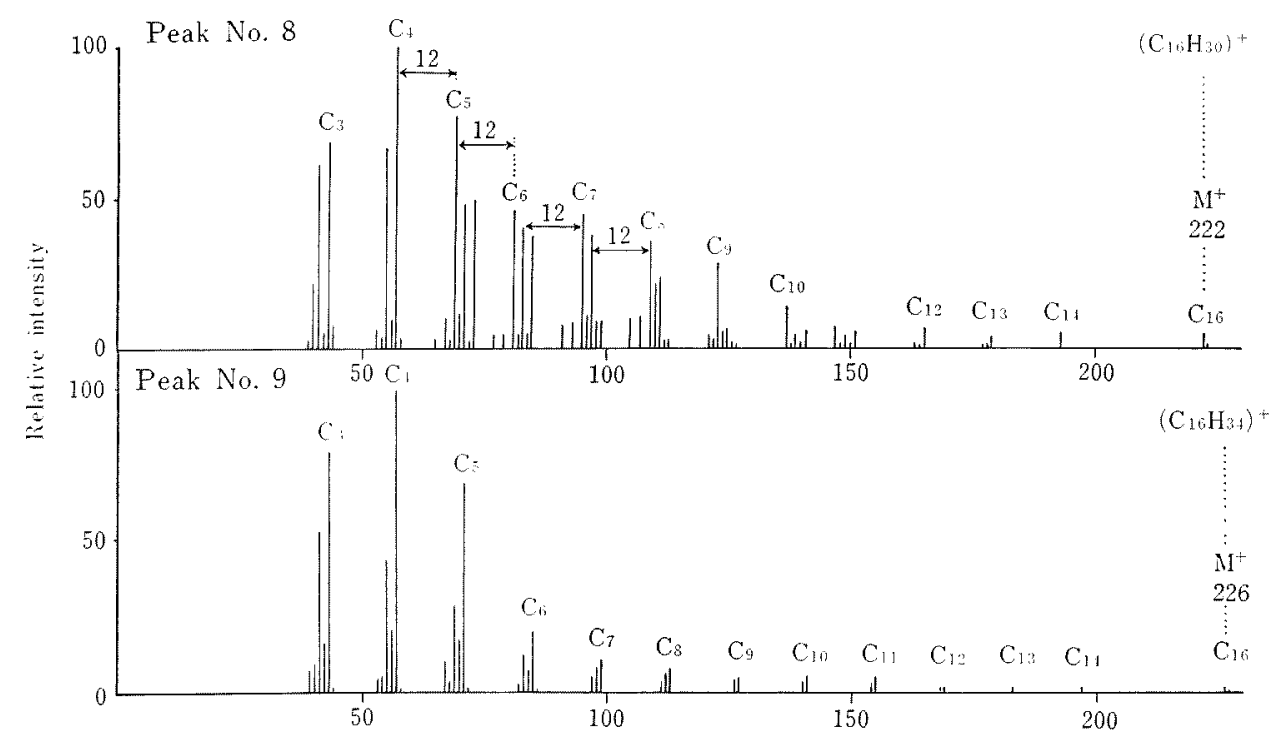

Fig. 5. Mass Fragmentation of Peaks 8 and 9 as Typical Examples of Alkadiene and $n$-Alkane.

Apparatus, Hitachi RMU-GL; chamber voltage, $70 \mathrm{eV}$; ion-source temperature, $150^{\circ} \mathrm{C}$; and separator temperature, $100^{\circ} \mathrm{C}$. 


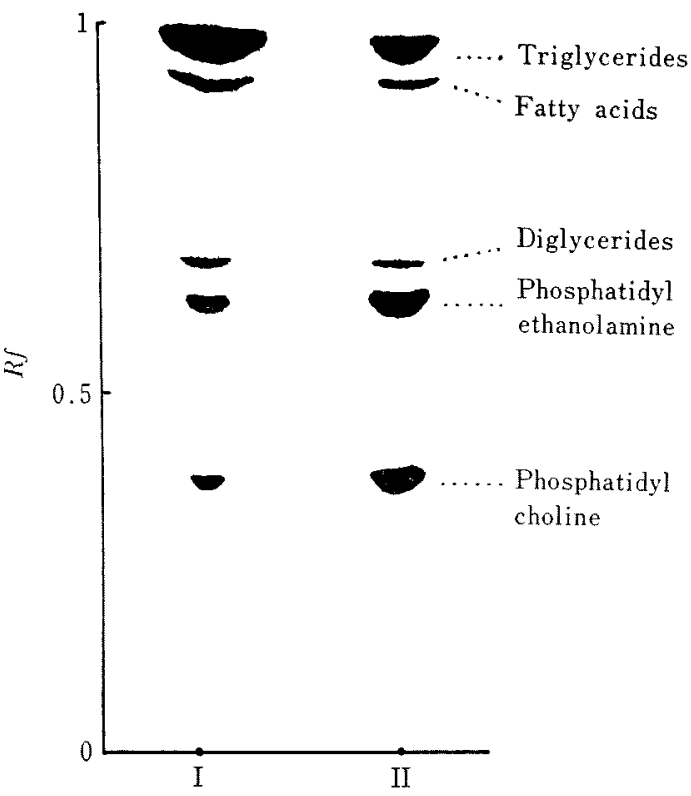

FIG. 6. Thin-layer Chromatograms of Ether-extractable Fractions I (left) and II (right).

Adsorbent, silica-gel G (merck); solvent, chloroformmethanol-water $(65: 25: 4)$; coloring reagent, $5 \%$ phosphomolybdic acid in ethanol.

of Ether-extractable fractions I and II were analysed.

As the first step we investigated the aliphatic hydrocarbon fraction by use of gas chromatography and obtained the results as shown in Fig. 4. The peaks were assigned, tentatively based on their retention times compared with those of corresponding authentic hydrocarbons

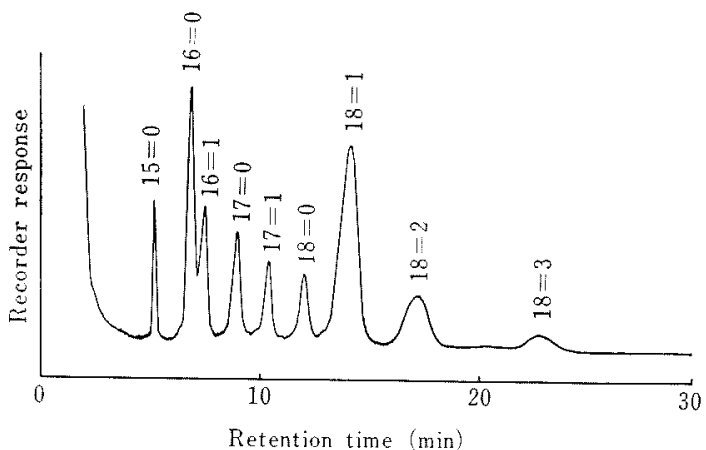

FIG. 7. Fatty Acid Composition of Ether-extractable Fraction I. ${ }^{a)}$

a) Ether-extractable fraction II showed a similar pattern of the fatty acid composition.

Each figure in the chart shows the carbon and doublebond numbers of the fatty acid.

Apparatus, Shimadzu GC-4A; column, 15\% diethyleneglycol succinate polyester $(0.3 \times 200 \mathrm{~cm})$; temperature, $190^{\circ} \mathrm{C}$; and carrier $\left(\mathrm{N}_{2}\right)$ flow-rate, $30 \mathrm{ml} / \mathrm{min}$.

or conclusively by a combined gas chromatographic-mass spectrometric system (GC-MS), to such compounds as listed in Table I. In Fig. 5, typical examples of the mass fragmentation of peaks 8 and 9 (Fig. 4) are shown to differentiate the alkadiene from the $n$-alkane on the basis of the difference between $C_{n}$ and $\mathrm{C}_{n+1}(n=3,4, \ldots)$ as well as between the mass numbers of both parent peaks. The above identification shows that both samples (Ether-extractable fractions I and II) contain at least 17 hydrocarbons bearing carbon

Table II. $R f$-Values of Spots on Thin-Layers

\begin{tabular}{ccccccl}
\hline & \multicolumn{7}{c}{ Conditions } & Identity \\
\cline { 2 - 6 } Spot & $\mathrm{A}$ & $\mathrm{B}$ & $\mathrm{C}$ & $\mathrm{D}$ & $\mathrm{E}$ & \\
\hline $\mathrm{a}$ & 0.64 & 0.15 & 0.77 & - & - & 3-Formylindole \\
$\mathrm{b}$ & 0.48 & 0.24 & 0.71 & - & - & Indole-3-acrylic acid \\
$\mathrm{c}$ & - & - & - & 0.37 & 0.64 & Ubiquinone Q8 \\
\hline
\end{tabular}

A: Silica gel $\mathrm{G}$; isopropanol-ammonia-water $(100: 5: 10)$.

B: Silica gel $G$; chloroform- $96 \%$ acetic acid $(95 ; 5)$.

C: Silica gel $\mathrm{G}$; chloroform-methanol-acetic acid $(75: 20: 5)$.

D: Silica gel $G$; acetone-hexane (5:95).

E: Paraffin oil-impregnated silica gel ${ }^{28)}$; acetone-water $(95: 5)$.

Spots a and b: Violet and brownish yellow, respectively, in responses to DMAB reagent $(5 \% p$-dimethylaminobenzaldehyde in $50 \%$ ethanol made $6 \mathrm{~N}$ in $\mathrm{HCl}$ ).

Spot c: Positively responded to a saturated solution of $\mathrm{SbCl}_{3}$ in chloroform, to a $5 \%$ solution of phosphomolybdic acid in ethanol, to a $0.02 \%$ solution of leucomethylene blue in acetone containing a bit of metallic $\mathrm{Zn}$, and to $98 \% \mathrm{H}_{2} \mathrm{SO}_{4}$. 
numbers from 11 to 24 . It was found, however that their relative contents were different from each other in that sample II showed somewhat larger contents of higher molecular hydrocarbons $\left(\mathrm{C}_{20} \sim \mathrm{C}_{24}\right)$ than sample I (Fig. 4).

The aromatic hydrocarbon fraction obtained through the procedures of Fig. 3 was subjected to silica-gel $G$ (Merck), thin-layer chromatography and developed with cyclohexane until the frontal line travelled a distance of $16 \mathrm{~cm}$ in height. At least three spots $(\mathrm{a}, \mathrm{b}$, and c) having $R f$ values of $0.75,0.68$, and 0.55 respectively were detected with the aid of ultraviolet ray $(365 \mathrm{~m} \mu)$ radiation from a handysized Manasule lamp. The $R f$ values were in agreement with those of authentic phenanthrene, anthracene, and pyrene, respectively. Each spot was extracted with ether to prepare a sample for mass spectrometric analysis. The parent peaks were, $m / e 178$ (spot a), m/e 178 (spot b), and m/e 202 (spot c). The modes of the mass fragmentation of spots $a, b$, and $c$ were identical with those of authentic anthracene, phenanthrene, and pyrene, respectively.

The silica gel-adsorbed, chloroform-extracted fraction (Fig. 3) was found to be constituted mostly by lipids, when investigated by thin-layer chromatography under the conditions reported by Malins and Mangold ${ }^{3}$ for the separation and detection of various lipids (Fig. 6).

The fatty acid composition of these lipids was investigated. The chloroform-extracted fraction (from Ether-extractable fraction I or II), after evaporation of chloroform, was dissolved in $1 \mathrm{~N} \mathrm{KOH}$ in ethanol and the solution allowed to stand for $1 \mathrm{hr}$ under the reflux condition. After having removed the unsaponifiable substances by ether extraction, an aqueous solution of fatty acid salts formed was acidified to $\mathrm{pH} 2$ with $\mathrm{H}_{2} \mathrm{SO}_{4}$ to liberate a fatty acid mixture. After its methylation by use of diazomethane in the usual manner, the resulting mixture of fatty acid methyl esters was analyzed by gas chromatography. Figure 7 shows the result obtained with sample I. Sample II gave a similar result. In both cases it may well be noted that significant amounts of odd carbon-numbered fatty acids are detected including $n$-pentadecanoic, $n$-heptadecanoic, and heptadecenoic acids.

Other ingredients easily detectable in the chloroform-extracted fraction (Fig. 3) are such compounds that develop a brownish or violet color by treatment with $5 \%$ p-dimethylaminobenzaldehyde (DMAB) in ethanol-6 $\mathrm{N} \mathrm{HCl}$ (1:1). The thin-layer chromatographic probes using three different solvent systems (A, B, and $\mathrm{C}$ in Table II) disclosed that this fraction contained at least four DMAB-positive compounds. Among those, two compounds giving spots $a$ and $b$ (Table II) were in agreement with authentic 3-formylindole and indole3 -acrylic acid both in the $R f$ values and in the color qualities.

The total amount of the DMAB-positive compounds, determined by the method of Spies and Chambers, ${ }^{4}$ was $360 \mathrm{mg} / 100 \mathrm{~g}$ (as tryptophan) in Ether-extractable fraction II.

Also, in the chloroform-extracted fraction a compound (spot $\mathrm{c}$ in Table II) was found which corresponded to a certain ubiquinone in respect to its color responses to various reagents (Table II) and its ultraviolet spectrum in the neighborhood of $272 \mathrm{~m} \mu$. A probe employing reverse phase thin-layer chromato-

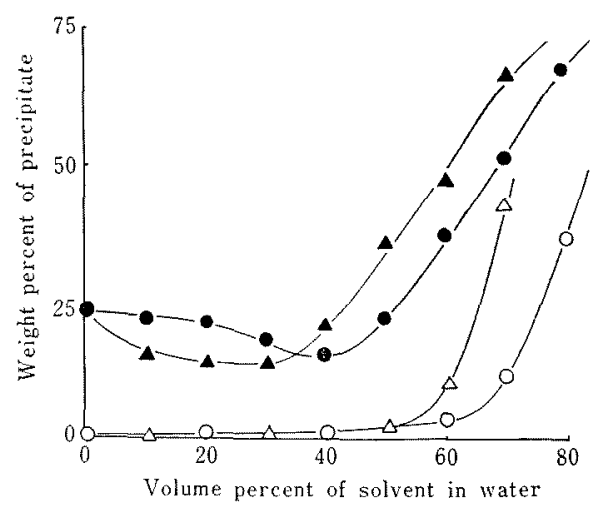

FIG. 8. Percent Yields of Precipitates after Treatment with Various Concentrations of Aqueous Solvents.

- - plastein sample/aqueous ethanol; $\bigcirc-0$, control sample/aqueous ethanol; $\mathbf{\Delta - \Delta ,}$, plastein sample/aqueous acetone; $\Delta-\Delta$, control sample/ aqueous acetone. 
graphy ${ }^{5}$ demonstrated that this compound was identical with an $n=8$ homologue of ubiquinone (Table II). According to the method of Folkers et al.,6) it was found that this ubiquinone amounted to $1.6 \mathrm{mg} / 100 \mathrm{~g}$ of Etherextractable fraction II.

\section{Plastein-synthetic process}

The peptic hydrolysate after treatment with ether was incubated with Bioprase under the aforementioned conditions to synthesize a plastein. Methods of using aqueous solutions of the warranted solvents, ethanol and acetone, were applied to yield the plastein. One part of a whole plastein-reaction product was preliminarily diluted with three parts of water and made homogeneous by stirring vigorously. To the homogenized suspension was added 36 parts of an aqueous ethanol (or acetone) solution of a given concentration, so that the resulting sample was increased by 40 times in volume and at the same time showed a varying concentration (zero $\sim 80 \%$ ) in ethanol (or acetone). Figure 8 shows a relationship between ethanol (or acetone) concentration and the amount of the plastein precipitated.

In the case of the aqueous ethanol treatment the plastein yield was minimum at the ethanol concentration of $40 \%$ Either above or below this concentration the yield shows a rapid or gradual increase. It is interesting
Table 1II. Amino Acid Composition ${ }^{a)}$ of the $50 \%$ Ethanol-soluble, Water-insoluble Plastein (P) Compared with Its Substrate (S)

\begin{tabular}{|c|c|c|c|c|}
\hline & Amino acid & $\mathrm{S}$ & $\mathbf{P}$ & $\mathrm{P} / \mathrm{S}$ \\
\hline \multirow{14}{*}{ 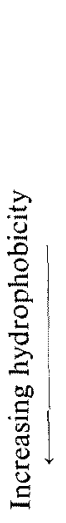 } & Aspartic acid & 1.23 & 0.85 & 0.69 \\
\hline & Glutamic acid & 1.35 & 0.84 & 0.62 \\
\hline & Lysine & 0.87 & 0.68 & 0.78 \\
\hline & Arginine & 0.40 & 0.39 & 0.98 \\
\hline & Glycine & 1 & 1 & 1 \\
\hline & Serine & 0.76 & 0.79 & 1.04 \\
\hline & Threonine & 0.62 & 0.57 & 0.92 \\
\hline & Alanine & 1.31 & 1.32 & 1.01 \\
\hline & Valine & 0.76 & 1.18 & 1.55 \\
\hline & Leucine & 0.91 & 2.98 & 3.27 \\
\hline & Proline & 0.23 & 0.68 & 2.44 \\
\hline & Phenylalanine & 0.45 & 1.39 & 3.09 \\
\hline & Tyrosine & 0.50 & 0.60 & 1.20 \\
\hline & Isoleucine & 0.62 & 1.15 & 1.85 \\
\hline
\end{tabular}

to note that by treatment with water only the plastein yield rises by about 1.5 times over the lowest value $(15.0 \%)$ to get $23.0 \%$ as seen in Fig. 8. This result suggests that a certain hydrophobic plastein fraction occurs during the reaction and precipitated by treatment with water.

We prepared a $50 \%$ ethanol-soluble, waterinsoluble fraction and analyzed for the amino acid composition. As Table III shows, it was

Table IV. Properties of Prectpitate (Plastein) and Supernatant ${ }^{a}$

\begin{tabular}{|c|c|c|c|c|c|}
\hline \multirow{3}{*}{$\begin{array}{c}\text { Final concentration } \\
\text { of ethanol } \\
\%(v / v)\end{array}$} & \multirow{3}{*}{$\begin{array}{c}\text { Plastein } \\
\text { quality } \\
\%\end{array}$} & \multicolumn{4}{|c|}{ Supernatant } \\
\hline & & \multirow{2}{*}{$\begin{array}{c}\text { Content ratio } \\
\text { of sugars } \\
\%\end{array}$} & \multicolumn{2}{|c|}{ Optical density } & \multirow{2}{*}{$\begin{array}{l}\text { Intensity of } \\
\text { fluorescence }\end{array}$} \\
\hline & & & $340 \mathrm{~m} \mu$ & $400 \mathrm{~m} / \iota$ & \\
\hline 0 & 81.0 & 92.5 & 0.775 & 0.311 & Strong \\
\hline 10 & 78.7 & 80.0 & 0.749 & 0.302 & Strong \\
\hline 20 & 74.6 & 72.5 & 0.743 & 0.297 & Medium \\
\hline 30 & 74.0 & 77.5 & 0.740 & 0.288 & Medium \\
\hline 40 & 73.5 & 67.5 & 0.711 & 0.278 & Medium \\
\hline 50 & 62.1 & 60.0 & 0.702 & 0.262 & Medium \\
\hline 60 & 56.7 & 55.0 & 0.679 & 0.260 & Medium \\
\hline 70 & 51.8 & 37.5 & 0.451 & 0.222 & Weak \\
\hline 80 & 51.0 & 25.0 & 0.233 & 0.153 & Slight \\
\hline
\end{tabular}

a) Experimental procedures described in text.

b) $\mathrm{N} \times 6.25(\%)$

c) Ratio to a total amount of sugars. 
found that when compared with the substrate this fraction is composed of smaller amounts of hydrophilic amino acids such as aspartic acid, glutamic acid and lysine, and of larger amounts of hydrophobic amino acids such as leucine and phenylalanine. It appears that this fraction, though not so large in quantity, is similar to the prolamine concerning ethanol solubility in aqueous ethanol.

\section{Plastein quality evaluation}

Each of the plasteins precipitated by treatment with various concentrations of aqueous ethanol was determined for the nitrogen content as a yardstick of the quality. Expressing the quality by multiplying the nitrogen value by a factor of 6.25 for convenience, we obtained the data as a function of ethanol concentration (Table IV). This result shows that the quality gets higher with decreasing ethanolconcentration; the quality gets highes by treatment with water and lowest by $80 \%$ ethanol treatment, there being a difference by almost 1.6 times between the two extremes. In response to this, there was a reverse relation concerning the contents of the impurities (nonplastein substances) in the supernatant fraction. Probing this fraction for the suger content, color intensity (optical densities at $340 \mathrm{~m} /$ and at $400 \mathrm{~m} \mu$ ), and fluorescence, we obtained the results shown in the other half of Table IV.

\section{DISCUSSION}

Concerning the interaction between proteins and low-molecular substances, modern biochemical studies have provided much information basic to the understanding of the characteristic aspects of protein activities in systems; the protein-lipid interaction is apparently a growing subject of interest in the viewpoints not only of biochemistry but also of food research in practice. On this subject a number of papers ${ }^{i n}$ 'in have been presented among which a report from Nielsen, ${ }^{7)}$ for example, has described protein-bound lipids in terms of the "difficultly extractable lipids" that occur in a soybean flour preparation after treatment with $n$-hexane. Some other papers ${ }^{9 \sim 11}$ have suggested in this relation that the proteinbound lipids in most cases contain phosphatides as their major constituents. According to Salem, ${ }^{12)}$ the long-range effects including the charge-charge interaction, dipolepolarizable group interaction and London-van der Waals dispersion force account mostly for the protein-phosphatide binding; apparently the third force relates to the so-called hydrophobic force in effect so far as the aqueous system is concerned. Wishnia ${ }^{13)}$ have clearly observed the presence of the hydrophobic interaction in an experiment using an aliphatic hydrocarbon ( $n$-butane) as an indicator for surveying the binding with a protein (bovine serum albumin). A similar, more comprehensive, experiment has been carried out by Mohammedzadeh-k et al. ${ }^{14 !}$ They have shown that various short-chain aliphatic hydrocarbons and some aromatic hydrocarbons are capable of binding with proteins through the hydrophobic force. Probably, the surface hydrophobic regions on the protein molecules may be responsible for such a binding, so far as the experimental conditions adopted by these workers are concerned. When treated, however, under severer conditions, proteins may well suffer from some conformational changes to occlude lipids and related substances in a more complicated manner. The substances occluded in this manner is considered to become resistant to the extraction by such a conventional method as the Soxhlet technique. Arai et $a l^{15)}$ studied the interaction between a denatured protein preparation of soybean and its beany flavor components, $n$-hexanal and $n$-hexanol, and demonstrated that the bound flavors, not removable by extraction under mild conditions, were liberated and removed only when the protein preparation was partly hydrolyzed enzymatically. Noguchi et al. $^{16\rangle}$ reported that various lipids, as well as flavor components, were liberated and extracted from defatted soyben flour through its protease treatment.

The present study includes an application 
of the above information to the quality improvement of a crude preparation of petroprotein.

The ether-treated protein (Fig. 2) was apparently free from ether-extractable substances. However, when treated with pepsin, this protein preparation further liberated various lipids and related compounds totalling $0.27 \%$ on a weight basis (Fig. 2). These compounds may well be considered as having been occluded in the protein molecules in a bound state.

Making a comparison between the free and protein-bound hydrocarbons (Fig. 4), we found that longer-chain compounds such as eicosane, heneicosane, docosane, tricosane and tetracosane were relatively richer in the latter case than in the former case. Although the abovementioned report of Mohammedzadeh- $\mathrm{k}^{14}$ ) describes that the hydrocarbons bearing appropriate degrees of chain-length, e.g., $\mathrm{C}_{5}$, are predominant over shorter- or longerchain hydrocarbons in the ability of interacting with proteins at the hydrophobic surfaces, our case is probably that some physically tangled modes of interaction take place between the longer-chain hydrocarbons and the unfolded molecular chains of proteins.

A similar interaction may be possible between polycyclic aromatic hydrocarbons and proteins, since we found anthracene, phenanthrene, and pyrene in Ether-extractable fraction II. In this relation several compounds typified by 3, 4-benzpyrene have been worried about their carcinogenic activities,, 18) although such compounds were undetectable in our sample.

Other ether-extractable impurities identified in our samples are two indoles and a ubiquinone (Table II). From the standpoint of preparing a high quality plastein it is considered that the less their contents, the better the quality.

The main constituents of the bound lipids are somewhat different from those of the free lipids, in that phospholipids, i.e., phosphatidyl ethanolamine and phosphatidyl choline, are more prominent in the former case than in the latter case (Fig. 6). Important may be a result that in both cases the lipids are composed of significant amounts of odd carbonnumbered fatty acids such as pentadecanoic, heptadecanoic and heptadecenoic acids (Fig. 7).

The co-existence of the lipids and related substances is of nuisance also in a viewpoint of the proteinase action. Inhibition due to the so-called "non-productive binding" is known to take place against proteinases when the proteolytic systems contain hydrophobic substances. ${ }^{19,20}$ Such inhibition is observed as well in the case where the plastein reaction is concerned. ${ }^{211}$ Thus, both protein-hydrolytic and plastein-synthetic processes are affected unfavorably, if intervened by the lipids and related substances.

The ether-treated hydrolysate (Fig. 2) may be assessable in a sense that this carries already no hydrophobic impurities. However, the protein-hydrolytic process gave rise to another demerit that the resultant hydrolysate showed a strongly bitter taste. This phenomenon is, in most points of view, of little value, as the authors and coworkers ${ }^{22,23}$ have previously mentioned in regard to a similar, bitter taste problem encountered as a result of the enzymatic hydrolysis of soybean protein.

The present study deals also with an application of the plastein reaction to yield a tasteless plastein by solvent-aided precipitation, rather than with some basic works undertaken recently concerning the mechanism of the reaction $^{21)}$ and the physicochemical properties of plasteins. ${ }^{24)}$

In the plastein reaction it is a characteristic point that a part of the reaction product is apt to precipitate from an aqueous medium, whilst the control, i.e., an incubation mixture without enzyme, remains water-soluble even after the incubation. It may be noted in addition that a part of the water-insoluble product gets rather soluble in an aqueous ethanolic medium, as if this were a prolamine. Such a phenomenon is understood in part from the result that the $50 \%$ ethanol-soluble plastein, compared with the control, indicates markedly larger amounts of the hydrophobic amino 
acid residues (Tab'e III). As a yardstick of the hydrophilic-hydrophobic property of protein, Tanford ${ }^{25)}$ has evaluated the contribution of the side-chains of individual amino acid residues. According to his data, amino acids such as proline, leucine, isoleucine and phenylalanine ( $c$. Table III) are recognizable as being strongly hydrophobic in comparison with glycine taken as a basis. The information may be interstingly relative with the properties of the prolamine-like plastein.

As Fig. 8 shows, the plastein is more or less precipitable from the aqueous solvent system. Considering this as resulting from the occurrence of the hydrophobic aggregation between or among higher-molecular peptides formed, it is unlikely that hydrophilic substances including sugars suffer co-precipitation. The plastein quality estimable from the nitrogen content (multiplied by 6.25) rised, in our experiment by about $50 \%$ by treatment solely with water, as a result of having left sugars in the supernatant fraction (Table IV). A more or less degree of contamination by sugars seems to be inevitable to petroproteins, as Mitsuda et $a .^{26,27)}$ have reported in their detailed studies on the methods of obtaining protein fractions from single cells. On the other hand, the present study may afford another method of obtaining a product containing a decreased amount of residual sugars. The result shown in Table IV suggests that some coloring and fluorescent compounds which, though unidentified, are speculated as soluble hemes, flavonoids, and the like, act like sugars and move into the supernatant when the sample is treated with water or water-rich ethanol (acetone). Thus, such a treatment is effective in obtaining a plastein (precipitate) having a higher quality.

\section{REFERENCES}

1) M. Yamashita, S. Arai, J. Matsuyama, M.
Gonda, H. Kato and M. Fujimaki, Agr. Biol. Chem., 34, 1484 (1970).

2) M. Dubois, K. A. Gilles, J. K. Hamilton, P. A. Rebers and F. Smith, Anal. Chem., 28, 350 (1956).

3) D. C. Malins and H. K. Mangold, J. Am. Oil Chem. Soc., 37, 576 (1960).

4) J. R. Spies and D. C. Chambers, Anal. Chem., 21, 1249 (1949).

5) H. Wagner, L. Hörhammer and B. Dengler, J. Chromatog., 7, 221 (1962).

6) F. R. Koniuszy, P. H. Gale, A. C. Page and K. Folkers, Arch. Biochem. Biophys., 87, 298 (1960).

7) K. Nielsen, J. Am. Oil Chem. Soc., 37, 217 (1960).

8) R.W. Burley, Can. J. Biochem. Biophys., 41, 389 (1963).

9) J. G. Ponte, Jr., V. A. de Stefanis and R. H. Cotton, Cereal Chem., 44, 427 (1967).

10) J. Cerbulis, J. Agr. Food Chem., 16, 646 (1968).

11) Y. Pomeranz, R. P. Tao, R. C. Hoseney, M. D. Shogren and K. F. Finney, ibid., 16, 974 (1968).

12) L. Salem, Can. J. Biochem. Biophys., 40, 1287 (1962).

13) A. Wishnia, Proc. Natl. Acad. Sci., 48, 2200 (1962).

14) A. Mohammedzadeh-k, R. E. Feeny and L. M. Smith, Biochim. Biophys. Acta, 194, 246 (1969).

15) S. Arai, M. Noguchi, M. Yamashita, H. Kato and M. Fujimaki, Agr. Biol. Chem., 34, 1569 (1970).

16) M. Noguchi, S. Arai, H. Kato and M. Fujimaki, J. Food Sci., 35, 211 (1970).

17) J. W. Howard, T. Fazio and R. H. White, $J$. Agr. Food Chem., 16, 72 (1968).

18) J. W. Howard and T. Fazio, ibid., 17, 527 (1969).

19) W. B. Lawson, J. Biol. Chem., 242, 3397 (1967).

20) F. Yoshida and M. Nagasawa, Bull. Agr. Chem. Soc. Japan, 20, 257 (1956).

21) S. Tanimoto, M. Yamashita, S. Arai and M. Fujimaki, Agr. Biol. Chem., 36, 1595 (1972).

22) M. Fujimaki, M. Yamashita, Y. Okazawa and S. Arai, J. Food Sci., 35, 215 (1970).

23) S. Arai, M. Noguchi, S. Kurosawa, H. Kato and M. Fujimaki, ibid., 35, 392 (1970).

24) K. Aso, M. Yamashita, S. Arai and M. Fujimaki, Abstracts of Papers, The Annual Meeting of the Agricultural Chemical Society of Japan, Sendai, April 1972, p. 324.

25) C. Tanford, J. Am. Chem. Soc., 84, 4240 (1962).

26) H. Mitsuda, M. Sugiura, K. Yasumoto and B. Tonomura, J. Jap. Soc. Food Nutr., 23, 62 (1970).

27) H. Mitsuda, M. Sugiura, K. Yasumoto and B. Tonomura, ibid., 23, 66 (1970). 